\title{
Natural history of spheno-orbital meningiomas
}

\author{
Peerooz Saeed • Wouter R. van Furth • Michael Tanck • Fabio Kooremans • \\ Nicole Freling • Geert I. Streekstra • Noortje I. Regensburg • \\ Jan Willem Berkelbach van der Sprenkel • Saskia M. Peerdeman • \\ Jakobus J. van Overbeeke • Maarten P. Mourits
}

Received: 24 June 2010 / Accepted: 8 November 2010/Published online: 1 December 2010

(C) The Author(s) 2010. This article is published with open access at Springerlink.com

\begin{abstract}
Background To investigate the natural history and the growth rate of spheno-orbital meningiomas (SOMs).

Methods Ninety patients with a diagnosis of SOM were included, and patient charts and imaging were evaluated. In a subset of 32 patients, volumetric studies were performed. Results The median follow-up for the entire group was 4 years (range, 1-15); the mean age was 47.8 (range, $26-93$ ) years; $94 \%$ of the patients were female. The most common clinical signs and symptoms were proptosis $(93 \%)$, visual deterioration $(65 \%)$, retro-bulbar pain (23\%) and diplopia $(6 \%)$. In $35 \%$ of patients in this series, no visual deterioration occurred, and in $30 \%$ only mild proptosis was present. The median annual growth rate of the SOMs in the subset of 32 patients was $0.3 \mathrm{~cm}^{3} /$ year (range, $0.03-1.8 \mathrm{~cm}^{3} /$ year). We assessed a trend for more
\end{abstract}

P. Saeed $(\varangle) \cdot$ F. Kooremans $\cdot$ N. I. Regensburg $\cdot$ M. P. Mourits Orbital Centre, Academic Medical Centre,

University of Amsterdam,

P.O. Box 22660, 1100 Amsterdam, The Netherlands

e-mail: p.saeed@amc.uva.nl

W. R. van Furth

Neurosurgical Centre Amsterdam,

Location Academic Medical Centre, University of Amsterdam,

Amsterdam, The Netherlands

\section{Tanck}

Department of Clinical Epidemiology,

Biostatistics and Bioinformatics Academic Medical Centre,

University of Amsterdam,

Amsterdam, The Netherlands

N. Freling $\cdot$ G. I. Streekstra

Department of Radiology, Academic Medical Centre,

University of Amsterdam,

Amsterdam, The Netherlands rapid tumour growth in younger patients and found the initial volume of the tumour $(r h o=0.63)$ and of the soft tissue component $(\mathrm{rho}=074)$ to be significantly related to the growth rate.

Conclusion SOMs are slow-growing tumours that cause primarily proptosis and visual deterioration. In a significant number of patients, these tumours cause minimal discomfort and symptomatology. Therefore, in the absence of risk factors, we advocate a "wait and see" policy. For patients with large SOMs or with a large soft tissue component at first visit or with fast growing $\mathrm{SOMs}\left(>1 \mathrm{~cm}^{3} /\right.$ year), a follow-up examination every 6 months is indicated.

Keywords Spheno-orbital meningiomas · Orbital meningiomas · Natural history · Volumetry · Imaging · Orbitaltumors

\section{G. I. Streekstra}

Department of Biomedical Engineering and Physics, Academic Medical Centre, University of Amsterdam, Amsterdam, The Netherlands

J. W. B. van der Sprenkel

Department of Neurosurgery, University Medical Centre Utrecht, Utrecht, The Netherlands

S. M. Peerdeman

Neurosurgical Centre Amsterdam,

VU University Medical Centre Amsterdam,

Amsterdam, The Netherlands

J. J. van Overbeeke

Department of Neurosurgery,

University Medical Centre Maastricht,

Maastricht, The Netherlands 


\section{Introduction}

Spheno-orbital meningiomas (SOMs) are secondary tumours of the orbit that originate from the dura of the sphenoid wing bone. They exhibit interosseous tumour growth, leading to hyperostosis and a thin, carpet-like soft tissue growth at the dura $[11,17]$. The most common signs and symptoms associated with SOMs are visual deterioration, proptosis, and cosmetic deformity.

The biological behaviour of SOMs varies. In some patients, minor symptoms are present whereas in others a devastating loss of vision, severe proptosis, and disfiguring due to rapid growth is observed $[1,4,5,11,12,14-17,19]$. Surgical treatment of these tumours is associated with a high morbidity and a mortality rate of up to $6 \%$. In addition, the recurrence rate of SOMs is higher than that of meningiomas in other locations $[1,4,5,11,12,14-17,19]$. The majority of published studies on SOMs concern results of the surgical treatment of these tumours. Little information is available on the natural history of the tumours and the outcomes for patients who do not undergo surgical intervention.

In this study, we analysed clinical characteristics, imaging results, and annual growth of SOMs prior to any intervention except biopsy in patients diagnosed with SOM.

\section{Patients and methods}

We examined the records of 90 patients seen between 1980 and 2008 at the Orbital Centre of the Academic Medical Centre, University of Amsterdam $(n=61)$, and at the University Medical Center in Utrecht $(n=29)$. Patients with nonhyperostotic sphenoid wing meningiomas, clinoid meningiomas, or primary optic nerve sheath meningiomas were excluded from this study.

All patients underwent ophthalmological examinations to assess visual acuity (Snellen notation). Colour vision was determined quantitatively by dividing the total number of Ishihara plates correctly identified by the total number of plates tested. Ocular motility was also assessed. Diplopia was considered present when the patient experienced double vision (in any gaze direction) that disappeared with one eye closed. The degree of proptosis was determined using a Hertel exophthalmometer. In Amsterdam, an Oculus Hertel (Oculus Optikgeräte $\mathrm{GmbH}$, Wetzlar, Germany) was used and in Utrecht, a Zeiss Hertel (Carl Zeiss, Jena, Germany) was used. However, in each patient, always the same instrument was used.

Funduscopy and evaluation of the optic disc were performed on all patients. Because perimetry examinations to assess visual field were not performed in all patients, we did not include these examinations in our analysis.
All patients underwent detailed neurological examinations. All 90 patients underwent computed tomography, and 75 also underwent magnetic resonance imaging (MRI). We documented the extent of hyperostosis and involvement of the optic canal (OC), superior orbit fissure (SOF), and infraorbital fissure. Gadolinium-enhanced and fatsuppressed MRI sequences were obtained in three planes to analyse the extent of infiltration of the dura mater, intracranial extension, and intra- and extraconal orbital and periorbital involvement. We had histopathologic material available in 77 patients: 66 from debulking surgery in a later stage and 11 from biopsies.

From the late 1990s onwards, all SOM patients underwent MRI studies; thus, serial MRI studies of 32 consecutive patients were available. Volumetric measurements were performed only on these patients. In this group, the volume $(V)$ and annual growth rate (AGR) of each SOM prior to any intervention were measured using at least two follow-up MRI scans. The calculations were performed on enhanced axial $\mathrm{T}_{1}$ slices of 1.3 to $6 \mathrm{~mm}$ sing Scion Image $\mathrm{J}$ software developed at the US National Institutes of Health. The enhanced area of the tumour in each slice image was measured by manual tracing of the tumour boundaries. The sum of the enhanced areas was then multiplied by the slice interval of the MRI series to obtain the total tumour volume. Dura mater, bone, and soft tissue were included in the measurements. Soft tissue component was also measured separately.

AGR values in cubic centimetres per year $\left(\mathrm{cm}^{3} /\right.$ year $)$ were determined using the following formula:

$\mathrm{AGR}=\frac{[\mathrm{d} V(\text { latest }- \text { initial })]}{t}$

where $\mathrm{d} V$ (latest-initial) is the difference in volume (in $\mathrm{cm}^{3} /$ year) between the most recent and initial imaging studies, and $t$ is the time (in years) of the follow-up period.

\section{Statistical analysis}

Patient characteristics and variables are described as mean or median with range where appropriate. Differences in continuous or categorical variables between groups were analyzed using the Wilcoxon-Mann-Whitney or Fisher's exact test, respectively. Spearman's correlation coefficients were calculated between the tumour growth and age, the volume of tumour, soft tissue component at the first diagnosis, and the length of the follow-up period. For all tests, probability values of less than 0.05 were considered to indicate statistical significance. All analyses were carried out using the Statistical Package for Social Sciences (SPSS software version 16 for Windows; SPSS, Inc., Chicago, IL). 


\section{Results}

The mean age of the patients was 47.8 years (range, 2693). There were $85(94 \%)$ females and five $(6 \%)$ males. In 49 patients the right orbit was involved and in 41 patients the left orbit was involved. The most common co-morbidity was thyroid dysfunction. In all, three patients were hypothyroid and 11 patients were hyperthyroid, three of whom also had Graves' orbitopathy. Six patients had a history of breast cancer. Café au lait spots were observed in two patients, and one patient had been diagnosed with neurofibromatosis type 2 .

Median follow-up for the entire group was 4 years (range, 1-15). Median follow-up was 2 years (range, 0-12) for the group that eventually underwent surgery and 7 years (range, 3-15) for the group that was observed only.

Signs and symptoms

We documented 39 patients (41\%) with an initial visual acuity in the affected eye of 0.8 or better. Three patients (3\%) presented with no light perception in the affected eye. The presenting visual acuity is summarised in Table 1.

In all, 29 patients had optic discs with some degree of disc atrophy, 28 presented with disc oedema, and 33 had normal discs. (Figure 1). Choroidal folds were present in only three patients. With the exception of six patients, the majority $(93 \%)$ of the patients in this series exhibited proptosis as measured by the Hertel exophthalmometer. Mean proptosis difference between the affected and contralateral eye at presentation was $5.5 \mathrm{~mm}$ (range, 014) for all patients. With regard to other signs and symptoms, five patients $(6 \%)$ exhibited diplopia at presentation, and one patient presented with diplopia after 2 years of follow-up. Generalised headaches and focal retro-orbital pain were observed in 21 patients $(23 \%)$. No patients died because of SOM.

Imaging

We analysed images of the 75 patients with both a computed tomography scan and at least one MRI. Eighteen patients (24\%) exhibited more than one intracranial meningioma. All patients showed involvement of the sphenoid wing, dura mater, and the orbit. (Figure 2). Fifty-seven patients $(76 \%)$ had some intracranial soft tissue component and $39(52 \%)$ were intraorbital, ten of which were intraconal. Fifty-four patients (72\%) had SOMs that involved the periorbit, and 52 meningiomas extended into the orbital roof. A total of 68 tumours involved the SOF, 56 involved the OC, 29 involved the infraorbital fissure, and 30 extended into the anterior clinoid process. Nine tumours invaded the cavernous sinus (Fig. 2; Table 1).
Table 1 Signs and imaging characteristics of spheno-orbital meningiomas
$V A$ visual acuity, $T X$ treatment, $O Z$ orbitozygomatic resection, $N A$ not applicable, $O C$ optic canal, SOF superior orbit fissure

\begin{tabular}{|c|c|c|c|c|c|}
\hline & \multicolumn{2}{|c|}{ Patients } & \multirow[t]{2}{*}{ Percent } & \multirow[t]{2}{*}{ Significant deterioration } & \multirow[t]{2}{*}{ Surgery } \\
\hline & $N=90$ & $N=75$ & & & \\
\hline \multicolumn{6}{|l|}{ VA } \\
\hline $1.0-0.8$ & 39 & & 41 & 8 & 18 \\
\hline $0.7-0.4$ & 27 & & 30 & 27 & 27 \\
\hline $0.3-\mathrm{CF}$ & 23 & & 26 & 18 & 18 \\
\hline NLP & 3 & & 3 & 0 & 3 \\
\hline \multicolumn{6}{|l|}{ Proptosis (mm) } \\
\hline $0-1$ & 6 & & 7 & 0 & 0 \\
\hline $2-4$ & 28 & & 23 & 7 & 12 \\
\hline $5-10$ & 49 & & 54 & 12 & 47 \\
\hline $10-14$ & 7 & & 8 & 1 & 7 \\
\hline \multicolumn{6}{|l|}{ Location (imaging) } \\
\hline Dura & & 75 & 100 & NA & NA \\
\hline Periorbit & & 70 & 93 & NA & NA \\
\hline SOF & & 68 & 91 & NA & NA \\
\hline $\mathrm{OC}$ & & 60 & 80 & NA & NA \\
\hline Orbital roof & & 52 & 70 & NA & NA \\
\hline Anterior clinoid & & 30 & 40 & NA & NA \\
\hline IOF & & 29 & 39 & NA & NA \\
\hline Cavernous sinus & & 12 & 16 & NA & NA \\
\hline Intraconal & & 8 & 11 & NA & NA \\
\hline
\end{tabular}



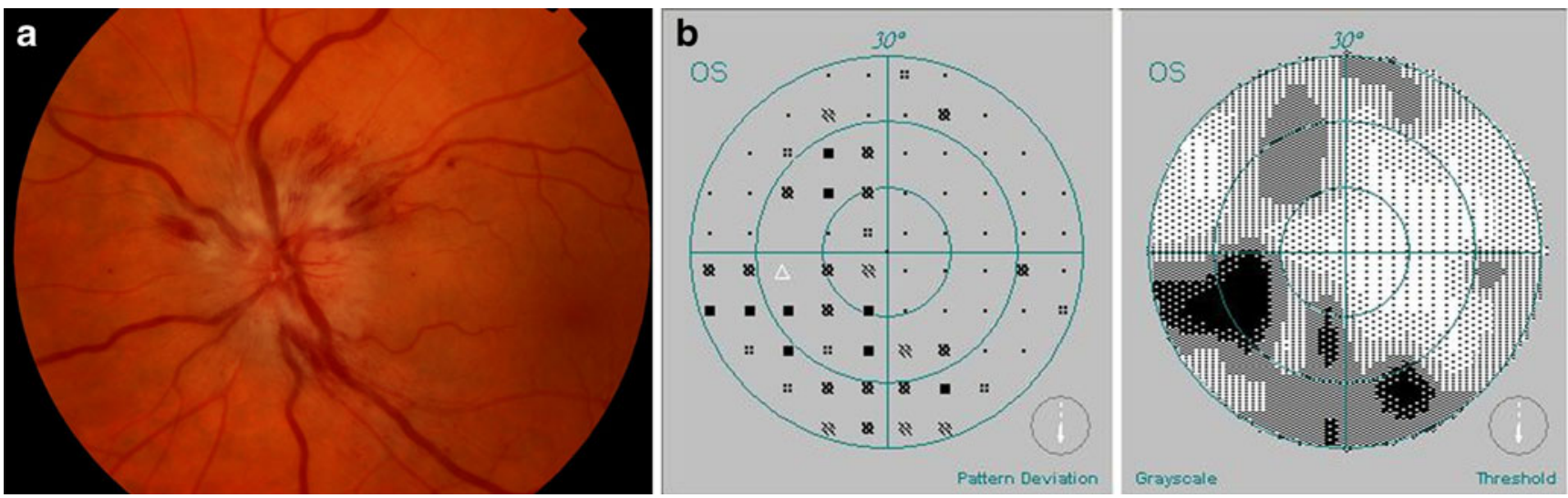

Fig. 1 a Fundus photograph with optic disc edema. b Humphrey visual fields demonstrates inferior arcuate defects in the same patient

Natural history and progression

\section{Volumetric studies}

Our cohort for volumetric studies consisted of 32 patients. The mean age at presentation was 48 years (range, 37-69). All patients were female. The median follow-up period was 9.3 years (range, $4-28$ ). The average initial tumour volume was $6.9 \mathrm{~cm}^{3}$ (range, 1.8-13.60), and the median annual growth rate was $0.3 \mathrm{~cm}^{3} /$ year (range, $0.03-1.8$ ). Although a trend for faster growth in younger patients was present, the difference was not statistically significant $(r h o=0.171$; $p=0.346$ ). AGR was significantly positively correlated with volume of soft tissue component $(\mathrm{rho}=0.714)$ and the initial tumour volume $(r h o=0.633)$. AGR increased with increasing initial tumour volume; however this relationship was not linear (Fig. 2). Six SOMs in this series had an AGR of more than $1 \mathrm{~cm}^{3} /$ year (range, 1.10-1.8). All of these tumours had a large soft tissue of more than $40 \%$ of volume. (Figure 3)

\section{Characteristics of visual deterioration}

To assess the natural history prior to treatment, we analysed the effect of the tumour on visual acuity in patients managed with observation alone.

In the entire group 31 patients (35\%) maintained a visual acuity of 0.8 or better in the affected eye during follow-up (mean, 4.8 years; median, 4 years). Within this group, 22 patients were followed for 5-13 years, and 15 patients were followed for 3 years (Fig. 4).

Overall, $59(65 \%)$ patients (eyes) developed optic neuropathy. Five eyes in this series went blind without any intervention; three of them had had no light perception at the time of presentation. Each of these five patients was known to have longstanding optic neuropathy caused by stenosis of the OC. The approximate mean time between the diagnosis of optic neuropathy by the ophthalmologist and assessable deterioration of vision was 38 months (range, 14-50).

Compression of the optic nerve caused by OC stenosis was most commonly associated with visual deterioration and was the most common cause of disc oedema and atrophy, occurring in 55 out of 59 patients (92\%). However, OC involvement (hyperostosis) was not always associated with visual deterioration. In patients who had no visual deterioration, the percentage of OC involvement was $65.8 \%$ whereas in patients with visual deterioration, it was $85.3 \%$. This difference was not statistically significant $(p=0.235)$. Although there was a correlation between visual deterioration and amount of proptosis, the correlation was not significant $(p=0.145)$. Four patients exhibited opticopathy with measured proptosis of 10-14 $\mathrm{mm}$. Upon imaging, this group of patients showed no involvement of the OC.

\section{Characteristics of proptosis}

Twenty-seven patients (30\%) maintained a proptosis of less than $4 \mathrm{~mm}$ in a median follow-up period of 4 years (range, 3-15 years). (Figure 5) Only seven patients underwent surgery because of disfiguring proptosis without any visual deterioration. For the group of patients who eventually underwent surgery, mean proptosis was $5.89 \mathrm{~mm}$ (range, $0-14)$. The proptosis did not differ in the group who underwent eventually surgery and observation group $(p=0.102)$

There was also no correlation between age and visual deterioration and amount of proptosis.

\section{Discussion}

In this study SOM occurred exclusively in females (94\%). This female predominance is much higher than for other locations of meningiomas. Optic nerve sheath meningiomas have a female incidence of $80 \%[13,18]$. 

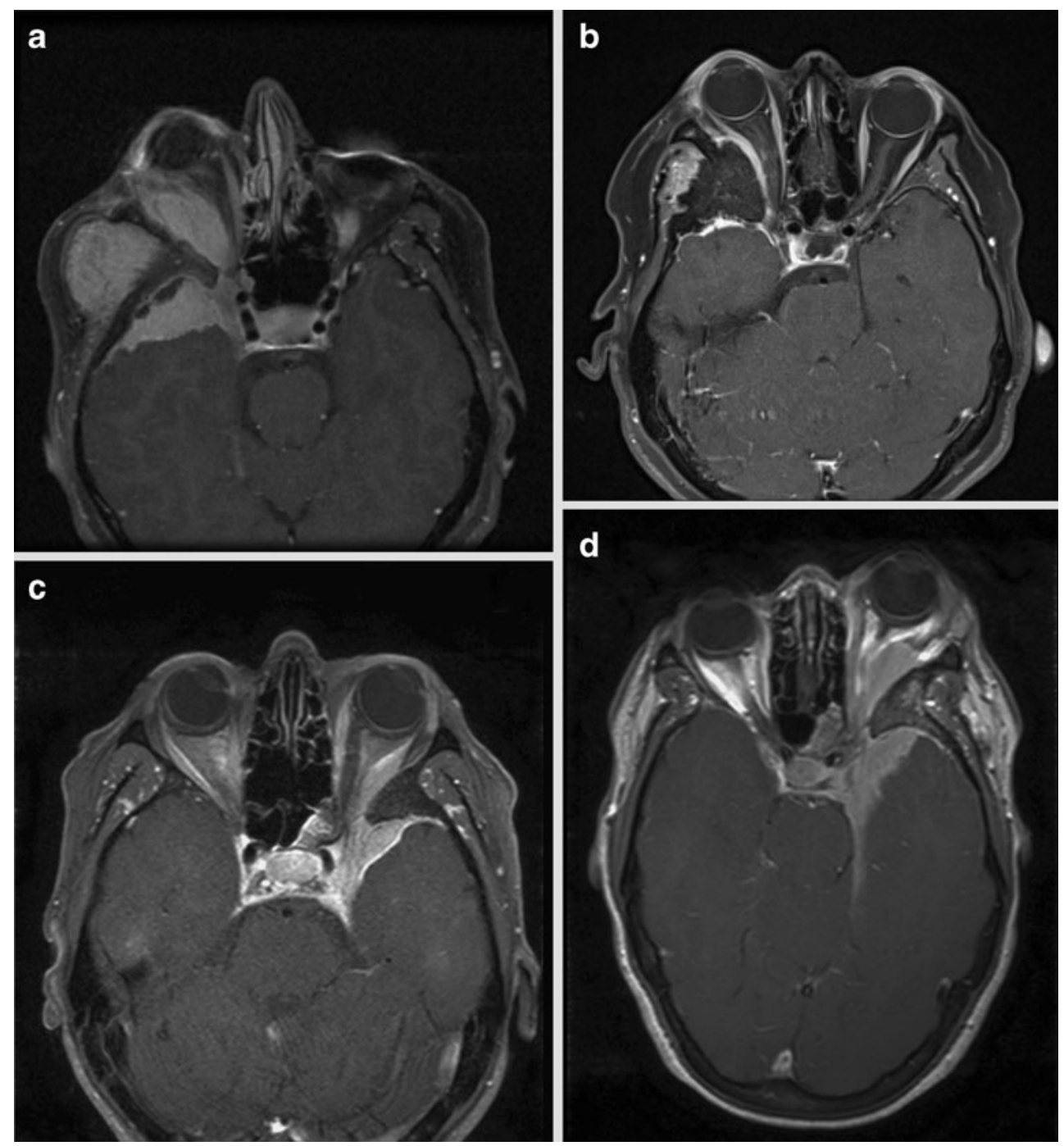

Fig. 2 Gadolinium-enhanced axial T1-weighted MR fat suppression sequence obtained in a patient a with a large SOM consisting of soft tissue, b mainly with hyperostosis, $\mathbf{c}$ cavernous sinus extension, and $\mathbf{d}$ growing over the midline

Thyroid dysfunction was the most common association with SOM in these series (16\%). It is possible that combination of thyroid disease and proptosis has facilitated the early imaging.

SOMs cause tumour growth, leading to significant hyperostosis and a thin yet widespread soft tissue growth at the dura. Bony tumour growth can include the sphenoid, orbital roof, SOF, OC, and the anterior clinoid $[17,19]$. Some authors have differentiated between meningioma en plaque (a carpet-like growing tumour) and hyperostoting meningioma [2, 3]. More recently, however, MRI has revealed that these tumours represent a single entity $[1,4,5,12,14-17,19]$. MRI has also revealed soft tissue involvement in the intracranial region, the orbital content, the infratemporal fossa, and the temporal muscle [17, 19]. In this study, the majority of patients $(76 \%)$ had some intracranial soft tissue component or intraorbital component (39\%).

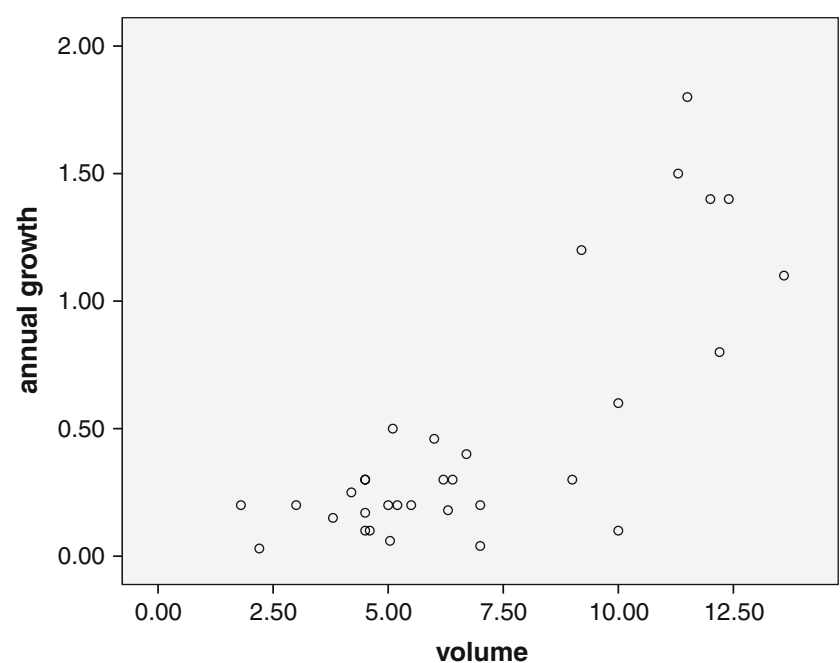

Fig. 3 Scatter plot showing the distribution of the annual growth and initial tumour volume 

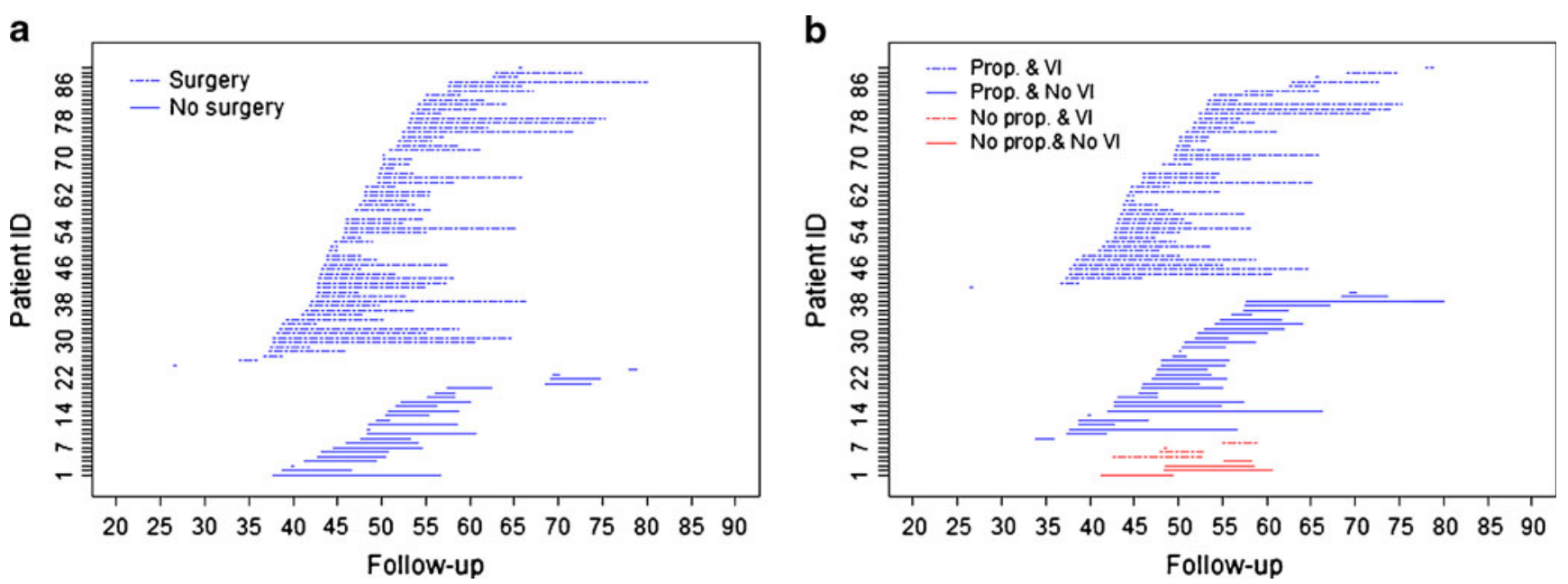

Fig. 4 Follow-up plot with the individual patients plotted against the age at the start and the end of the follow-up period. a Patients grouped by surgery, and $\mathbf{b}$ patients grouped by the presence of proptosis (prop) and visual impairment

The causes of hyperostosis in meningiomas are theorised to include vascular disturbances of the bone caused by the tumour, irritation of the bone without actual invasion, previous trauma, the production of bone by the tumour itself, and the stimulation of osteoblasts in normal bone by factors secreted by tumour cells. The most accepted cause of hyperostosis associated with SOM is direct tumour invasion, which could explain the disproportionate amount of hyperostosis relative to the dural size of the tumour $[9,10]$. In our series, hyperostosis was present in $100 \%$ of sphenoid wings, $70 \%$ of orbital roofs, $91 \%$ of SOFs, and $80 \%$ of OCs.

In this study, $35 \%$ of patients showed no visual deterioration after a follow-up period of up to 13 years. Unilateral visual deterioration was encountered in $65 \%$ of patients, generally because of optic nerve compression, not necessarily because of hyperostosis in the canal. The incidence of proptosis in this series was $95 \%$, with a mean of $5.5 \mathrm{~mm}$. Earlier studies reported incidence levels of proptosis between $33 \%$ and $86 \%$ [12, 16, 17, 19]. The high incidence of proptosis in our series can be explained by the fact that all of the patients had periodic Hertel exophthalmometry measurements. Even in patients with no clinically visible proptosis, proptosis can be identified radiographically [5]. These findings indicate that proptosis is the most common clinical sign of SOM. In a significant number of patients, proptosis may be the only clinical sign. Hyperostosis of the orbital walls, periorbital tumour invasion, intraorbital tumour, and venous stasis due to compression of the ophthalmic vein can all lead to proptosis. Diplopia was not a frequently encountered sign of SOM despite the fact that upon imaging $91 \%$ of patients had extension of meningioma into the SOF.

Most meningiomas are slow-growing tumours. However, the precise growth rate is difficult to assess [6].
Some SOMs grow slowly or seemingly not at all when assessed by planimetric measurement. Volumetric measurement may be a more accurate method of measurement, as tumours may grow in directions different from the planimetric axes $[6-8,20]$. A total of $32 \mathrm{SOMs}$ in our series exhibited an annual growth rate of $0.3 \mathrm{~cm}^{3} /$ year.
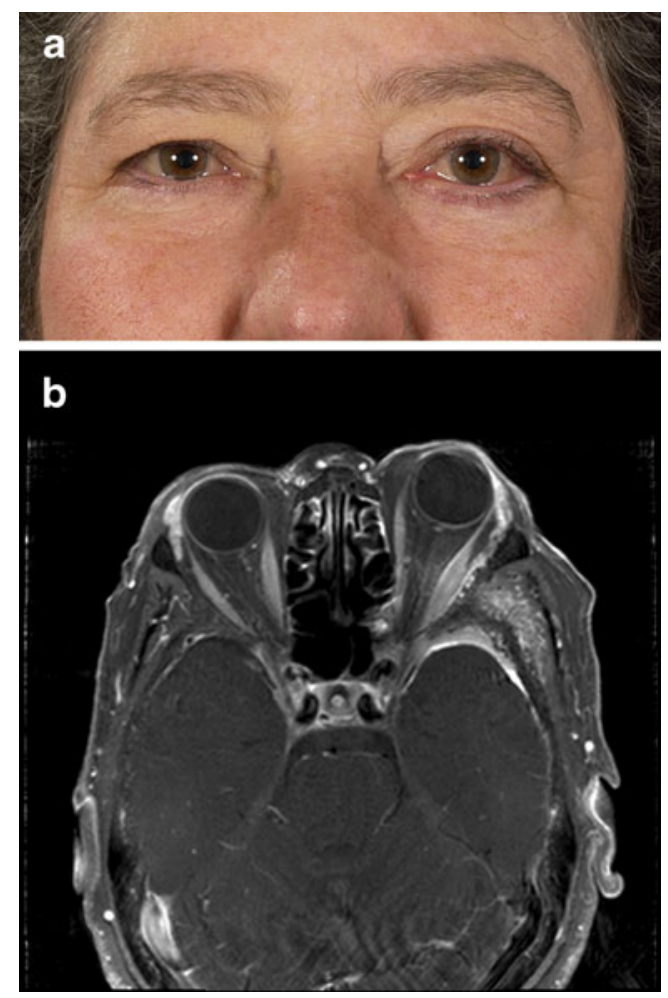

Fig. 5 a This 52-year-old woman presented with proptosis. b Gadolinium-enhanced axial T1-weighted MR fat suppression sequence obtained in this patient showed an SOM with hyperostosis. Proptosis and the SOM on imaging showed no progression during 6 years of follow-up 
The growth rate of SOMs is comparable with asymptomatic meningiomas $[6-8,20]$. SOMs often become symptomatic because of their proximity to the orbit and visual system.

Although SOMs are slow-growing tumours, some meningiomas grow much faster than others. In our series, there was a 60 -fold difference between the fastest and slowest growing SOMs. Although SOMs have a tendency to grow more slowly in older patients, the initial size of the tumour and of the soft tissue component volume were the only statistically significant predictor of its growth. It is possible that the soft tissue component itself may grow more rapidly than the hyperostotic portion of the tumour.

In conclusion, SOMs are slow-growing tumours, but SOMs with larger volumes and larger soft tissue component have faster growth rates. The most common sign of SOM in this study was proptosis (93\%) followed by visual deterioration $(65 \%)$. In $35 \%$ of patients in this series, no visual deterioration occurred, and in $30 \%$ only mild proptosis was present despite a considerable follow-up period. In a significant number of patients, SOM remains mild; therefore, an annual follow-up examination with ophthalmologic evaluation and MRI is indicated for most patients. For patients with faster growing SOMs $\left(>1 \mathrm{~cm}^{3} /\right.$ year), larger SOMs with large soft tissue component, or OC involvement, a follow-up examination every 6 months is indicated. Although SOMs are slow-growing tumours, in this series the mean age at diagnosis was 47.8 years and with many more years to live some SOMs may grow regrettably large in these patients preventive surgery is indicated.

\section{Conflicts of interest None.}

Open Access This article is distributed under the terms of the Creative Commons Attribution Noncommercial License which permits any noncommercial use, distribution, and reproduction in any medium, provided the original author(s) and source are credited.

\section{References}

1. Carrizo A, Basso A (1998) Current surgical treatment for sphenoorbital meningiomas. Surg Neurol 50:574-578

2. Castellano F, Guidetti B, Olivecrona H (1952) Pterional meningiomas en plaque. J Neurosurg 9:188-196

3. Cushing H (1922) The cranial hyperostosis produced by meningeal endotheliomas. Arch Neurol Psychiatry 8:139-196

4. De Jesús O, Toledo MM (2001) Surgical management of meningioma en plaque of the sphenoid ridge. Surg Neurol 55:265-269

5. Honeybul S, Neil-Dwyer G, Lang DA, Evans BT, Ellison DW (2001) Sphenoid wing meningioma en plaque: a clinical review. Acta Neurochir (Wien) 143:749-757
6. Jääskeläinen $\mathrm{J}$, Haltia M, Laasonen $\mathrm{E}$, Wahlstrom T, Valtonen S (1985) The growth rate of intracranial meningiomas and its relation to histology. An analysis of 43 patients. Surg Neurol 24:165-172

7. Nakamura M, Roser F, Michel J, Jacobs C, Samii M (2003) The natural history of incidental meningiomas. Neurosurgery 53:62-70

8. Olivero WC, Lister JR, Elwood PW (1995) The natural history and growth rate of asymptomatic meningiomas: a review of 60 patients. J Neurosurg 83:222-224

9. Pieper DR, Al-Mefty O, Hanada Y, Buechner D (1999) Hyperostosis associated with meningioma of the cranial base: secondary changes or tumor invasion. Neurosurgery 44:742-746

10. Pompili A, Derome PJ, Visot A, Guiot G (1982) Hyperostosing meningiomas of the sphenoid ridge-clinical features, surgical therapy, and long-term observations: review of 49 cases. Surg Neurol 17:411-416

11. Ringel F, Cedzich C, Schramm J (2007) Microsurgical technique and results of a series of 63 spheno-orbital meningiomas. Neurosurgery 60:214-221

12. Roser F, Nakamura M, Jacobs C, Vorkapic P, Samii M (2005) Sphenoid wing meningiomas with osseous involvement. Surg Neurol 64:37-43

13. Saeed P, Rootman J, Nugent RA, White VA, Mackenzie IR, Koornneef L (2003) Optic nerve sheath meningiomas. Ophthalmology 110:2019-2030

14. Sandalcioglu IE, Gasser T, Mohr C, Stolke D, Wiedemayer H (2005) Spheno-orbital meningiomas: interdisciplinary surgical approach, resectability and long-term results. J Craniomaxillofac Surg 33:260-266

15. Scarone P, Leclerq D, Heran F, Robert G (2009) Long-term results with exophthalmos in a surgical series of 30 sphenoorbital meningiomas. Clinical article. J Neurosurg 111:1069-1077

16. Schick U, Bleyen J, Bani A, Hassler W (2006) Management of meningiomas en plaque of the sphenoid wing. J Neurosurg 104:208-214

17. Shrivastava RK, Sen C, Costantino PD, Della RR (2005) Sphenoorbital meningiomas: surgical limitations and lessons learned in their long-term management. J Neurosurg 103:491497

18. Whittle IR, Smith C, Navoo P, Collie D (2004) Meningiomas. Lancet 363:1535-1543

19. Wilson WB (1981) Meningiomas of the anterior visual system. Surv Ophthalmol 26:109-127

20. Yoneoka Y, Fujii Y, Tanaka R (2000) Growth of incidental meningiomas. Acta Neurochir (Wien) 142:507-511

\section{Comment}

In their interesting review the Authors demonstrated that SOM are slowly growing tumours, as only six of the 32 patients undergoing MRI-based volumetric studies exhibited an AGR more than $1 \mathrm{~cm} 3 /$ year. However, only $35 \%$ of their whole series encountered no visual deterioration during the follow-up period. Moreover, since a diagnosis of optic neuropathy is made, assessable visual deterioration will occur within 38 months (range, 14-50). This occurred in 55 out of 59 patients who progressed to disc oedema and atrophy. I fully agree that for patients with fast growing SOM, large soft tissue component, or optic neuropathy, surgical intervention is indicated. Actually, in their series the median follow-up was 2 years for the group that eventually underwent surgery, and this is an expression of a clear surgical attitude.

Domenico d'Avella

Padova, Italy 
Cushing, in the 1938 compilation of his intracranial meningiomas, unforgettably demonstrated how large meningioma can grow and how it will eventually appear inside and outside the skull in populations totally uncovered by non-invasive neuroradiology-including the spheno-orbital meningioma (SOM) with monstrous exophthalmus and pterional bulge [1].

The authors present a series of 90 SOMs between 1980 and 2008 in two Dutch centers, with serial MRI data for volume growth rate in 32 cases. SOMs are rare (three per year in the present series) but many patients will come back for re-growth or re-consideration for the next 20 to 30 years. They authors are to be congratulated from placing an experienced ophthalmologist as the first author-proptosis and impaired visual acuity are the two leading symptoms [2] - and II-VI cranial nerve deficits quite frequent after surgical removal even in experienced hands [2]. Importantly, no visual deterioration occurred in $35 \%$ and only mild proptosis was present in $30 \%$ despite a considerable follow-up period-indicating a significant window for conservative treatment and follow-up only in these cases. Also importantly, a major soft tissue component indicated faster growth than a carpet of tissue over the hyperostotic sphenoid bone. The median follow-up was 2 years for those who eventually underwent surgery and 7 years for those observed only. Still, meningiomas are unpredictable, and from a mean age of 48 years at first diagnosis there are 40 more years to live and to grow.

Juha E Jääskeläinen

Kuopio, Finland

1. Cushing H, Eisenhardt L (1938) Meningiomas: Their Classification, Regional Behavior, Life History and Surgical and Results. Thomas, Springfield.

2. Ringel F, Cedzich C, Schramm J. Microsurgical technique and results of a series of 63 spheno-orbital meningiomas. Neurosurgery 2007;60(4 Suppl 2):214-21; discussion 221-2. 